This document is confidential and is proprietary to the American Chemical Society and its authors. Do not copy or disclose without written permission. If you have received this item in error, notify the sender and delete all copies.

\title{
Effect of pore structure on slippage effect in unsaturated tight formation using pore network model
}

\begin{tabular}{|r|l|}
\hline Journal: & Energy \& Fuels \\
\hline Manuscript ID & ef-2020-04044y.R2 \\
\hline Danuscript Type: & Article \\
\hline Author: & $25-$-Feb-2021 \\
\hline & $\begin{array}{l}\text { Complete List of Authors: } \\
\text { Engen, Minxia; China University of Petroleum Beijing College of Petroleum } \\
\text { Choungang; University of Aberdeen, School of Engineering } \\
\text { Development Northwest Branch } \\
\text { Zhang, Tao; China University of Petroleun-Beijing , } \\
\text { Wu, Keliu; China University of Petroleum Beijing } \\
\text { Feng, Dong; China University of Petroleum Beijing } \\
\text { Li, Xiangfang; China University of Petroleum Beijing }\end{array}$ \\
\hline
\end{tabular}

\section{SCHOLARONE Manuscripts}




\title{
Effect of pore structure on slippage effect in unsaturated tight formation using pore network model
}

\author{
Minxia He, ${ }^{\dagger,}$ Yingfang Zhou, ${ }^{\ddagger}, \|^{*}$ Bintao Chen, ${ }^{\S}$ Tao Zhang, ${ }^{\dagger *}$ Keliu Wu, ${ }^{\dagger}$ \\ Dong Feng, ${ }^{\dagger}$ and Xiangfang $\mathrm{Li}^{\dagger}$ \\ $\dagger$ State Key Laboratory of Petroleum Resources and Prospecting, China University of \\ Petroleum (Beijing), Beijing 102249, P.R. China. \\ $\$$ School of Engineering, University of Aberdeen, Aberdeen AB24 3UE, United Kingdom \\ " Department of Energy Resources, University of Stavanger, 4036, Norway \\ $\S$ Northwest Branch of PetroChina Research Institute of Petroleum Exploration \& \\ Development, Lanzhou 730020, China \\ * Corresponding author: Yingfang Zhou \\ Tao Zhang \\ E-mail address: yingfang.zhou@abdn.ac.uk \\ tobiascheuing@163.com
}

\begin{abstract}
The gas slippage phenomenon under dry conditions has been investigated extensively both numerically and experimentally. However, very limited research has focused on gas slippage behavior under wet conditions. Unlike conventional formation, the influence of water on the gas transport process can't be neglected in tight formations due to the comparable amount of thin water film attached along the rock surface. It is found experimentally that the gas slippage factor is positively related to water saturation if water saturation is small, while it decreases with water saturation if it is larger than a critical value. Most of the existing models failed to capture the measured downtrend of gas slippage factor with increasing water saturation, which resulted from water blocking or gas trapping phenomenon. In this work, a pore-scale network model is proposed to look at the water distribution characteristic and investigate the effect of water on the gas slippage factor. The proposed pore-scale model incorporates the
\end{abstract}


capillary dominated multiphase fluid distribution, real gas effect and gas transport mechanisms at pore-scale. Based on our pore network model, the effect of pore structure characteristics including the frequency of mean pore radius, size of mean pore radius, aspect ratio and coordination number on the gas slippage behavior are investigated and discussed in detail. Similar to previous experimental observations, the simulated gas slippage factor shows a nonmonotonic increase trend with water saturation, it starts to decrease under high water saturation and the critical water saturation depends on the pore structure factors. It increases with mean pore radius and coordination number but decreases with aspect ratio. We used the pore network model to investigate the effect of water phase on gas slippage behavior at the pore scale for the first time. It emphasized the predominance of water blocking and gas trapping phenomenon in the estimation of gas slippage factor at high water saturation.

\section{INTRODUCTION}

Permeability is a key parameter in the development of unconventional gas reservoirs such as coal seams, shale gas reservoirs and tight sandstones. Unlike conventional reservoirs, the gas permeability varies with the imposed pressure due to the gas slippage phenomenon. The pioneering work of Klinkenberg ${ }^{[1]}$ found a linear relationship between the measured gas apparent permeability and the reciprocal of the average pressure. The gas slip factor is evaluated as the slope of the line between apparent permeability and reciprocal of the average pressure, while the intrinsic permeability could be obtained by the y-intercept. Subsequently, this Klinkenberg gas permeability has been used extensively and it was found that the gas slip factor strongly depends on the intrinsic permeability, the gas property and the temperature ${ }^{[2-4]}$. In recent years, the classical Klinkenberg's theory was modified for ultra-lowpermeability porous media applications due to the deviations of gas permeability from it. Fathi et al. performed a numerical study of gas-phase advection in nano-capillaries and developed a double-slip Klinkenberg equation ${ }^{[5]}$. Moghadam and Chalaturnyk ${ }^{[6]}$ employed a more accurate boundary condition and a secondary slippage factor was introduced into the classic Klienkenberg slip theory. Safa et al. ${ }^{[7]}$ proposed an extended 
Kozeny-Carman-Klinkenberg model for micro/nano-porous media to incorporate the effect of pore connectivity. At the same time, several researchers ${ }^{[8-10]}$ have expanded the classical Klinkenberg theory to organic-rich porous media such as coal seams and shales. They took the effects of gas adsorption/desorption and deformation process into consideration.

As mentioned above, the gas slippage factor under dry conditions has been extensively investigated. However, very limited research is conducted on the gas slippage factor under wet conditions. In fact, initial water is always present in actual formations and its saturation could be relatively high in low permeability reservoirs due to the high resistance to initial gas migration and poor gas gravity differentiation ${ }^{[11,12]}$. Some experimental work revealed that the effective permeability to the gas phase would be significantly overestimated, as much as $30 \%{ }^{[13]}$, under wet conditions due to lack of two-phase slippage correction ${ }^{44,14-16]}$. Based on the experimental work, Fig. 1 summarizes the typical relationships between the gas slippage factor and water saturation ${ }^{[15]}$. As shown in this figure, Li and Horne ${ }^{[17]}$, Wu et al. ${ }^{[18]}$ and Li et al. ${ }^{[15]}$ found a positive relationship between the two-phase gas slippage factor and water saturation. However, Liu et al. ${ }^{[19]}$ claimed that there existed the critical water saturation. When water saturation exceeded the critical water saturation, the gas slippage factor started to decrease. In addition to experimental work, a few researchers have investigated the mechanisms of gas transportation behavior with the presence of water analytically ${ }^{[15,20-22]}$. Based on the Klinkenberg equation, Shi et al. ${ }^{[20]}$ presented an analytical model for the prediction of apparent permeability considering slippage effect, rock deformation and water saturation. Using a capillary tube model, Li et al. [21] investigated the effect of water saturation on the two-phase gas slippage factor in circular and angular pores. They found that for circular pores the effective radius decreases continuously with an increase in water saturation which leads to a rising slippage factor. And for angular pores, the cross-section shape changes due to the existence of corner water and the slippage factor could decrease as the water saturation increases. It is important to note that trends of slippage factor at high water saturation measured in the laboratory are not well explained yet which might originate from the 
significance of water condensation in smaller pores ${ }^{[15]}$. In reality, the existence of water, besides leading to a reduction in effective gas flow area, tends to snap off and result in hydrocarbon phase trapping ${ }^{[23]}$. And this process is influenced by the characteristics of the porous medium such as pore-size distribution, aspect ratio between pore-bodies and throats, connectivity and so on ${ }^{[24]}$. Thus, an appropriate pore-scale model needs to be established to investigate the mechanism of water effect on gas slippage behavior by incorporating the pore characteristics of the porous medium.

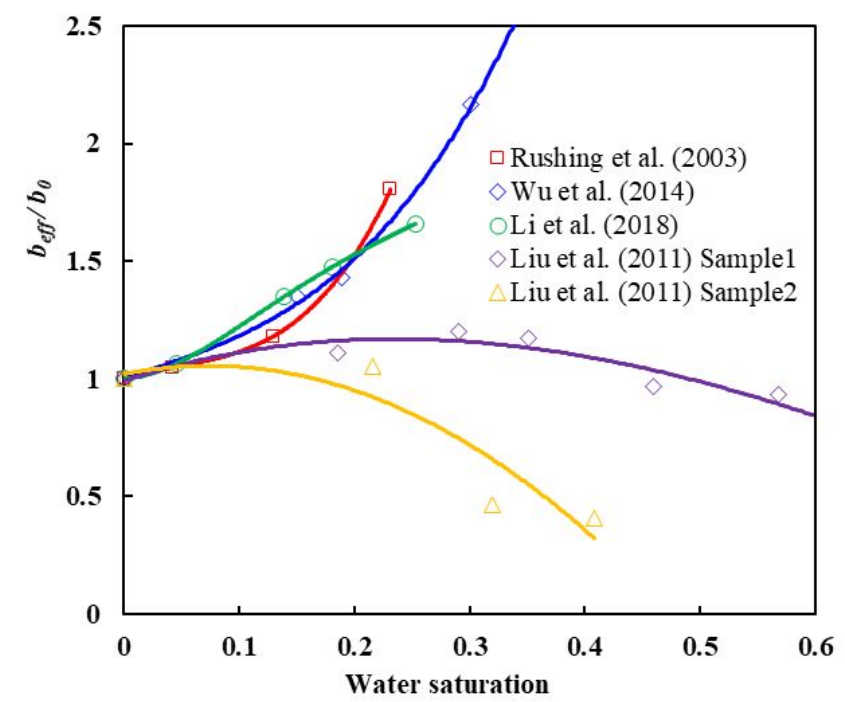

Fig. 1 The relationship between gas slippage factor and water saturation from previous research

Pore network model has been proven to be an efficient pore-scale method to simulate multiphase flow in porous media since the pioneering work of Fatt ${ }^{[25-27]}$. In recent years, many researchers extended the pore network model for unconventional porous media applications by incorporating the slippage effect, real gas effect, gas adsorption/desorption and so on [28-30]. They are mainly focused on single gas flow under dry conditions and gas-water two-phase relative permeability prediction. However, studies of the gas slippage factor under wet conditions haven't been found yet, and the effect of pore structure on the two-phase gas slippage factor remains unclear.

In this work, a quasi-static pore network model is established to investigate the two-phase gas slippage behavior at pore scale. We first constructed 3D stochastic networks and introduced the static pore network model for nano-porous media; here in this work, the static pore network model incorporates the dynamics of water distribution, real gas effect and gas transport mechanisms. We then validated the present pore 
network model by comparing the predicted result with experimental data under wet conditions. The effect of pore structure characteristics, such as pore-size distribution, aspect ratio and connectivity, on the two-phase gas slippage are investigated and discussed extensively. The work is then finished with a short summary and conclusion.

\section{STOCHASTIC PORE NETWORK GENERATION}

Pore network has been used to represent the pore system of reservoir rock and to conduct fluid flow simulation due to its computational efficiency. It could be generated either directly from pore space images (such as maximal ball method ${ }^{[31-33]}$, the medial axis based method ${ }^{[34]}$, or process-based method ${ }^{[35]}$ ) or by stochastic method ${ }^{[36]}$ which employs random number generator to produce networks that represent real rock statistically. In this work, the stochastic method is adopted to study the effect of structure characteristics on the slippage factor. Several algorithms have been proposed to generate the stochastic pore networks [37]. However, because of their latticestructured grids, they are not enough to represent the realistic and complex porous media (especially the coordination number). The method proposed by Raoof and Hassanizadeh ${ }^{[38]}$ improved the conventional lattice model by expanding the max connection number to 26 in three dimensions, which significantly requires more computational time. We have extended the algorithm proposed by de Chalendar et al. ${ }^{[36]}$ is in our work. The detailed process of pore network construction is described as the following steps:

(1) Provide Lx, Ly and Lz which represent the physical scale of the pore network model.

(2) Provide Nx, Ny and Nz which indicate the number of pore bodies.

(3) Generate pore bodies. Locate a pore body in a random position in the threedimensional space whose radius is sampled from the input pore radius distribution function. For each already entered pore body, if the distance between them is less than the sum of their radii and minimum throat length the location of the pore to be entered will be resampled. Continue until the number of pore bodies is reached.

(4) Generate the pore connectivity. Assign the coordination number which is sampled from the coordination number distribution function to each pore and connect 
its nearest pores one by one until the assigned coordination number is reached.

(5) Generate throats. For each connection between pores, sample aspect ratio from the input probability distribution function and calculate the throat radius and throat length.

(6) Calculate the physical property such as permeability and porosity. If the porosity is not satisfied, adjust the size of the physical bounding box or number of pores and continue from step (3) again.

The shape factor, representing the irregularity of cross-section, is a key parameter in pore networks ${ }^{[39]}$. It is defined as the ratio of cross-sectional area to perimeter squared. The values of shape factor for circle, square and equilateral triangle are $1 / 4 \pi$, $1 / 16$ and $\sqrt{3} / 36$, respectively. Because the fluid distribution in non-circular pores is complicated and the effect of pore shape on gas slippage factor is not considered here (the details are provided in Section 3), 3D stochastic networks with circular pores and throats will be generated to accurately reflect the effect of water on gas slippage factor in tight formations.

\section{PORE NETWORK MODELING OF GAS FLOW UNDER WET CONDITIONS}

The following assumptions have been made to establish the pore network model for gas transport through the nano-porous media that account for dynamics of water distribution, real gas effect and gas transport mechanisms. First, the pores and throats have a circular shape. Second, the relative humidity, defined as the ratio of the partial pressure of the vapor to saturated vapor pressure, is assumed to be identical throughout the porous media. Third, the influence of stress on the single pore size is not considered here which however could be extended for further work ${ }^{[29,40,41]}$. Finally, the effective hydraulic radius is adopted to calculate the conductance ${ }^{19-21,27}$ of gas flow rate through pores or throats. And in our model, the effective hydraulic radius is decreased due to the existence of adsorbed water film.

\subsection{Water distribution characteristic}

Two methods are commonly used to build the water saturation of gas-field cores under experimental conditions: core flooding (displacement or imbibition method), and 
adsorption or evaporation method ${ }^{[15]}$. To ensure a uniform distribution of water film in tight rocks, the water adsorption method is adopted to build water saturation in our pore network model.

Here we adopted Li's model $[15,21,22]$ which is based on the thermodynamic equilibrium between water and water vapor to estimate the fluid distribution inside pores and throats. The thickness of water film can be calculated using the following equation.

$$
\prod\left(h_{w}\right) V_{m}=-R T \ln \frac{P_{v}}{P_{o}}
$$

Where, $\Pi\left(h_{w}\right)$ is the disjoining pressure of water film, $\mathrm{Pa} ; h_{w}$ is the water film thickness, $\mathrm{m} ; V_{m}$ is the water molar volume, $\mathrm{m}^{3} / \mathrm{mol} ; R$ is the universal gas constant, $\mathrm{J} /(\mathrm{mol} \cdot \mathrm{K}) ; T$ is the temperature, $\mathrm{K} ; P_{v}$ is the equilibrium partial pressure of water vapor, $\mathrm{Pa} ; P_{o}$ is the saturated vapor pressure of water phase, $\mathrm{Pa}$.

For a circular pore, the effective disjoining pressure has to be revised as below due to the curved wetting film along the wall ${ }^{[42]}$.

$$
\begin{gathered}
\prod\left(h_{w}\right)=\frac{r}{r-h_{w}} \prod_{f l a t}\left(h_{w}\right)+\frac{\gamma}{r-h_{w}} \\
\prod_{f l a t}\left(h_{w}\right)=\prod_{m}\left(h_{w}\right)+\prod_{e}\left(h_{w}\right)+\prod_{s}\left(h_{w}\right) \\
\prod_{m}\left(h_{w}\right)=-\frac{A_{g w s}\left(15.96 \frac{h_{w}}{l}+2\right)}{12 \pi h_{w}^{3}\left(1+5.32 \frac{h_{w}}{l}\right)^{2}} \\
\prod_{e}\left(h_{w}\right)=\frac{\varepsilon_{r} \varepsilon_{o}}{8 \pi} \frac{\left(\varsigma_{1}-\varsigma_{2}\right)}{h_{w}^{2}} \\
\prod_{s}\left(h_{w}\right)=k \mathrm{e}^{-h_{w} / \lambda}
\end{gathered}
$$

Where $\prod_{\text {flat }}\left(h_{w}\right)$ is the disjoining pressure of water film on flat surface, $\mathrm{Pa} ; r$ is the capillary radius, $\mathrm{m} ; \gamma$ is the surface tension between water phase and gas phase, $\mathrm{N} / \mathrm{m} ; \prod_{m}\left(h_{w}\right)$ is the London-Van der Waals force, $\mathrm{Pa} ; \prod_{e}\left(h_{w}\right)$ is the electrical force, $\mathrm{Pa} ; \prod_{s}\left(h_{w}\right)$ is the structural force, $\mathrm{Pa} ; A_{g w s}$ is the Hamaker constant in gas-water- 
solid system, $\mathrm{J} ; l$ is the London wavelength, $\mathrm{m} ; \varepsilon_{r}$ is the relative permittivity of media, dimensionless; $\varepsilon_{o}$ is the permittivity in vacuum, $\mathrm{F} / \mathrm{m} ; \varsigma_{1}$ and $\varsigma_{2}$ are the electric potentials of the solid-water and water-gas interfaces respectively, $\mathrm{V} ; k$ is the coefficient for the strength of structural force, $\mathrm{N} / \mathrm{m}^{2} ; \lambda$ the characteristic length of water molecules, $\mathrm{m}$. The values of these parameters are displayed in Table 1 with reference to previous work ${ }^{[43]}$. Here, we assumed interfacial tension as a constant value, and its dependence ${ }^{[44,45]}$ on other variables will be included in our future work.

Table 1 Summary of parameters used in the calculation

\begin{tabular}{cccc}
\hline Parameter & Symbol & Unit & Value \\
\hline Hamaker constant of gas/water/solid & $A_{g w s}$ & $\mathrm{~J}$ & $1.0 \times 10^{-20}$ \\
London wavelength & $l$ & $\mathrm{~nm}$ & 100 \\
Dielectric permittivity of vacuum & $\varepsilon_{0}$ & $\mathrm{~F} / \mathrm{m}$ & $8.854 \times 10^{-12}$ \\
Relative permittivity of water & $\varepsilon_{r}$ & Dimensionless & 81.5 \\
zeta potential difference between solid/water & $\Delta \zeta$ & $\mathrm{mV}$ & 80 \\
interface and water/gas interface & $k$ & $\mathrm{~Pa}$ & $1.0 \times 10^{7}$ \\
Coefficient for the structural force & $\lambda$ & $\mathrm{nm}$ & 1.5 \\
Decay length & $\sigma$ & $\mathrm{mN} / \mathrm{m}$ & 72.5 \\
Interfacial tension & & &
\end{tabular}

As shown in this table above, the thickness of water film is a function of pore radius and humidity. For a given pore radius, it increases with the relative humidity until the critical humidity (when water film becomes unstable) is reached. And this critical thickness can be determined by ${ }^{[42]}$

$$
\left.\frac{\partial \prod(h)}{\partial h}\right|_{h=h^{*}}=0
$$

where $h^{*}$ is the critical water film thickness, m;

\subsection{Real gas property}

The gas properties in nano-porous material deviate significantly from that of bulk phase properties due to the non-negligible van der Waals forces between solid walls and gas molecules. It has been reported that the critical pressure and temperature would reduce when the pore size decreases ${ }^{[46,47]}$. In our paper, the improved Soave-RedlichKwong equation of state proposed by $\mathrm{Wu}$ et al. ${ }^{[47]}$ is adopted to estimate the 
compression coefficient and density of gas phase.

$$
P=\frac{R T}{V-b}-\frac{a(T)}{V(V+b)}
$$

Where $V$ is the molar volume of gas; $T$ is the temperature of the gas; $a(T)$ $=0.42748 R^{2} T_{c}^{2} \alpha(T) K_{f_{s}} / P_{c}$ is an attractive function which is dependent on temperature; $b=0.08664 R T_{c} /\left(P_{c} K_{f s}\right)$ is a repulsive parameter; $K_{f s}$ is the ratio of the interaction between gas molecules and walls to the gas intermolecular interaction; and $\alpha(T)$ is given by

$$
\alpha(T)=\left[1+\left(0.48+1.574 \omega-0.176 \omega^{2}\right)\left(1-T_{r}^{0.5}\right)\right]^{2}
$$

where $\omega$ is the acentric factor, dimensionless; $T_{r}$ is the reduced pressure, dimensionless.

The confinement effects on critical properties of gas inside nano-capillary can be expressed as ${ }^{[22,47]}$ :

$$
\begin{gathered}
T_{c c} / T_{c b}=1-1.2\left(\frac{D}{\sigma}-\frac{d_{a}}{\sigma}\right)^{-1 / 0.88} \quad(3<D / \delta \leq 50) \\
P_{c c} / P_{c b}=1-1.5\left(\frac{D}{\sigma}-\frac{d_{a}}{\sigma}\right)^{-1 / 1.6} \quad(3<D / \delta \leq 30) \\
D=2 r_{e f f} \\
P_{r}=\frac{P}{P_{c c}} \\
T_{r}=\frac{T}{T_{c c}}
\end{gathered}
$$

where $D$ is the effective pore diameter, $\mathrm{m} ; d_{a}$ is the thickness of the adsorbed gas layer along the surface of pores and set to zero due to the existence of a water film, $\mathrm{m} ; \quad \sigma$ is the Leonard-Jones parameter, $\mathrm{m} ; T_{c c}$ is the gas phase critical temperature considering the confinement effect, $\mathrm{K} ; P_{c c}$ is the gas phase critical pressure considering the confinement effect, $\mathrm{Pa} ; T_{c b}$ is the critical temperature of the bulk gas phase, $\mathrm{K}$; and $P_{c b}$ is the critical pressure of the bulk gas phase, MPa.

The gas viscosity can be described by the f-theory and expression is given below 
[48]

$$
\begin{gathered}
\mu=\mu_{0}+\mu_{f} \\
\mu_{0}=d_{1} \sqrt{T}+d_{2} T^{d_{3}} \\
\mu_{f}=\kappa_{r} p_{r}+\kappa_{a} p_{a}+\kappa_{r r} p_{r}{ }^{2}
\end{gathered}
$$

Where $\mu_{0}$ is the dilute gas viscosity; $\mu_{f}$ is the friction term; $p_{a}$ and $p_{r}$ are van der Waals attractive and repulsive terms respectively; $d_{1}, d_{2}, d_{3}$ are estimated parameters; $\kappa_{r}, \kappa_{a}, \kappa_{r r}$ are friction coefficients;

\section{3 bulk-gas flow}

Based on Knudsen number, defined as the ratio of mean free-path length of gas molecules and pore radius $K_{n}=\lambda / r$, the gas flow regime can be divided into continuum flow $\left(K_{n}<0.001\right)$, slip flow $\left(0.001<K_{n}<0.1\right)$, transition flow $\left(0.1<K_{n}\right.$ $<10)$ and Knudsen diffusion $\left(10<K_{n}\right)$. In a circular pore, the effective radius decreases due to the presence of water film and can be expressed

$$
r_{e f f}=r-h_{w}
$$

The mean free path of real gas molecules is obtained as ${ }^{[49]}$

$$
\lambda=\frac{\mu}{P} \sqrt{\frac{\pi Z R T}{2 M}}
$$

where $R$ is the gas constant, $\mathrm{J} /(\mathrm{mol} \cdot \mathrm{K})$, and $M$ is the gas molecular weight, $\mathrm{kg} / \mathrm{mol}$.

As the pressure drop along the pores and throats is very small, the properties of the gas phase inside single pores or throats are considered to be identical and the length effect on the calculation of mass flux and conductance is usually neglected, as is commonly employed in previous research ${ }^{[28-30]}$. Subsequently, the mass flux and the conductance of gas phase within cylindrical nanotubes can be calculated as below according to the gas flow model proposed by Beskok et al. which can be applied in the entire Knudsen range [50]:

$$
q_{m}=-\frac{1}{8} \frac{\rho_{g} \pi r_{e f f}^{4}}{\mu_{g}}\left[1+\frac{128}{15 \pi^{2}} \arctan \left(4 K n^{0.4}\right) K n\right]\left(1+\frac{4 K n}{1+K n}\right) \frac{\Delta p}{l}
$$




$$
g_{m}=\frac{1}{8} \frac{\rho_{g} \pi r_{e f f}^{4}}{\mu_{g} l}\left[1+\frac{128}{15 \pi^{2}} \arctan \left(4 K n^{0.4}\right) K n\right]\left(1+\frac{4 K n}{1+K n}\right)
$$

Where $\rho_{g}$ is the density of gas phase, $\mathrm{kg} / \mathrm{m}^{3} ; \mu_{g}$ is the viscosity of gas phase, $\mathrm{Pa} \cdot \mathrm{s} ; \Delta p$ is the pressure drop, $\mathrm{Pa} ; l$ is the length of the tube, $\mathrm{m}$;

\subsection{Calculation of apparent permeability}

Estimation of the total gas flow rate can be done by solving for the pressure at every pore element by using the mass conservation equation at every pore ${ }^{[39]}$

$$
\sum_{j} q_{i j}=\sum_{j} g_{i j}\left(P_{i}-P_{j}\right)=0
$$

With given total gas flow rate, the apparent permeability of the gas phase is calculated by ${ }^{[29]}$

$$
K=\frac{Q_{\mathrm{m}} \bar{\mu} L}{A\left(P_{\text {inlet }}-P_{\text {outlet }}\right) \rho_{\text {avg }}}
$$

Where $Q_{\mathrm{m}}$ is the mass flow rate of gas phase through the network, $\mathrm{kg} / \mathrm{s} ; A$ is the cross-sectional area in the flow direction, $\mathrm{m}^{2} ; \bar{\mu}$ is the average viscosity of the gas phase, $\mathrm{Pa} \cdot \mathrm{s} ; L$ is the length of the network, $\mathrm{m} ; P_{\text {inlet }}$ and $P_{\text {outlet }}$ are the pressure at inlet and outlet respectively, $\mathrm{Pa}$; and $\rho_{\text {ave }}$ is the average density of the gas phase, $\mathrm{kg} / \mathrm{m}^{3}$.

Due to the independence of viscosity and density on pressure, an iterative method is employed to solve the total gas flow rate. Fig. 2 illustrates the methodology used in our study to compute the apparent permeability. The key steps in the calculation are:

1. Initialization: Before starting the simulation, initial pressure and temperature are assigned to all throats and pores in the network.

2. Water saturation calculation: With a given humidity, the water film thickness is quantified for each pores and throats as shown in Section 3.1. And water saturation for the network is computed.

3. Calculation of pressure distribution at iterative step $k+1$ : The properties and conductance of gas phase at each element are updated explicitly according to pressure distribution at the step $k$. Then pore pressures at the step $k+1$ are solved from a linear set of equations defined from Eq.(22).

4. Calculation of the gas mass flow rate at the iterative step $k+1$ : The gas mass 
flow rate is computed by averaging the flow rates through inlet throats and outlet throats.

5. Calculation of the apparent permeability of gas phase: Step 3 and Step 4 can be performed in an iterative manner until a steady gas flow rate is reached. With the final gas flow rate, the apparent permeability of gas phase is found using Eq.(23). Here, the properties of gas phase are calculated under average pressure of inlet and outlet.

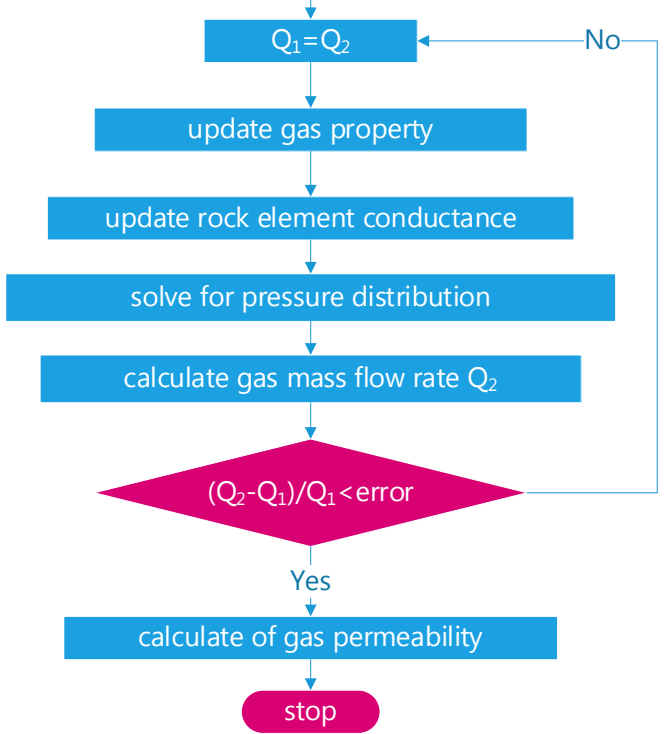

Fig. 2 Flowchart of the pore network used in this study to calculate the apparent gas permeability

Previous studies showed that the linear relationship between measured gas permeability and the reciprocal of the average pore pressure is still valid in tight gas cores ${ }^{[3,15,19]}$. For simplicity, the empirical Klinkenberg model ${ }^{[1]}$ as shown in Eq. (24) has been used extensively to describe the gas slippage effect under dry conditions.

$$
k_{a}=k_{\infty}\left(1+\frac{b_{k}}{P_{m}}\right)
$$

Where $k_{a}$ is the apparent permeability, $\mathrm{mD} ; k_{\infty}$ is the intrinsic permeability, $\mathrm{mD} ; b_{k}$ is the gas slippage factor, $\mathrm{MPa} ; P_{m}$ is the mean pressure of gas phase, $\mathrm{MPa}$. Similar to Eq.(24), the Klinkenberg model for gas flow with pre-adsorbed water can be formulated as $[15,20,51]$ 


$$
k_{a\left(S_{w}\right)}=k_{\infty}\left(S_{w}\right)\left(1+\frac{b_{\text {eff }}}{P_{m}}\right)
$$

where $k_{a\left(S_{w}\right)}$ is the apparent permeability of gas phase under wet condition, $\mathrm{mD}$; $k_{\infty}\left(S_{w}\right)$ is the effective intrinsic permeability under wet condition, $\mathrm{mD} ; b_{\text {eff }}$ is the gas slippage factor under wet condition, MPa.

Further, the intrinsic relative permeability and the apparent relative permeability are defined as ${ }^{[15]}$

$$
\begin{aligned}
& k_{r g-\infty}=\frac{k_{\infty}\left(S_{w}\right)}{k_{\infty}} \\
& k_{r g-a}=\frac{k_{a\left(s_{w}\right)}}{k_{\infty}\left(S_{w}\right)}
\end{aligned}
$$

\section{MODEL VALIDATION}

We used the experimental data of Bossier tight gas sandstone samples generated by Rushing et al. ${ }^{[13]}$ to validate our proposed pore network model. The relationships between gas apparent permeability and pressure at various water saturations were measured in Rushing et al's work. We modified the pore-network extracted from Berea sandstone ${ }^{[39]}$ to represent the tight sandstone due to lack of pore size distribution and pore structure for Bossier tight gas sandstone. As shown in Fig. 3, when the original Berea network is shrunk to the $1 / 250^{\text {th }}$ of its original size, the simulated apparent permeability matches well with experimental results at the dry condition. Then based on the modified network, we used our proposed pore network model to investigate the Klinkenberg effect under different water saturations. As shown in Fig. 3, the simulated apparent permeability agrees well with the experimental data at various unsaturated conditions.

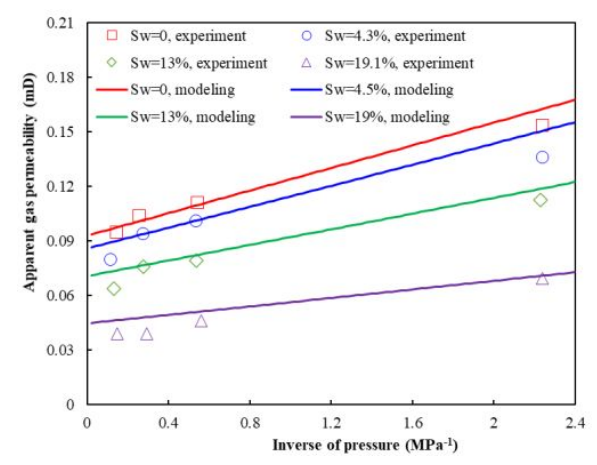


Fig. 3 Comparisons of the apparent permeability predicted by the proposed pore network model with the experimental data from Rushing et al. [13]

\section{RESULTS AND DISCUSSION}

In this section, based on the results simulated by the proposed model described above, the effect of pore structure characteristics, including the frequency of mean pore radius, the average pore radius, the aspect ratio and the coordinate number, on slippage effect is analyzed. We attempt to reveal the mechanisms and explain the experiment results from the pore scale. Here, a Gaussian distribution function is adopted to represent the pore size distribution and coordinate number distribution.

$$
f\left(r_{i}\right)=\frac{1}{\sqrt{2 \pi \sigma}} \exp \left(-\frac{\left(r_{i}-v\right)^{2}}{2 \sigma^{2}}\right)
$$

where $v$ and $\sigma$ is the mean and standard deviation.

\subsection{Frequency of mean pore radius}

In this part, we will investigate the effect of the frequency of mean pore radius on gas slippage effect by changing the standard deviation in Eq.(28), while the average pore radius remains at 30nm. As shown in Fig. 4, various stochastic networks with different frequency of mean pore radius are generated according to the PSD parameters listed in Table 2.

Table 2 PSD parameters for different standard deviation

\begin{tabular}{|c|c|c|c|c|c|}
\hline PSD parameters & $r_{\text {ave }} \mathrm{nm}$ & $\sigma \mathrm{nm}$ & $r_{\min } \mathrm{nm}$ & $r_{\max } \mathrm{nm}$ & $f_{\text {ave }}$ \\
\hline Base case & 30 & 0 & 30 & 30 & 1.0 \\
\hline Case 1 & 30 & 2 & 22.78 & 36.17 & 0.199 \\
\hline Case 2 & 30 & 4 & 14.01 & 40.27 & 0.099 \\
\hline Case 3 & 30 & 6 & 7.47 & 45.64 & 0.067 \\
\hline Case 4 & 30 & 8 & 3.39 & 51.50 & 0.050 \\
\hline Case 5 & 30 & 10 & 2.12 & 58.15 & 0.039 \\
\hline
\end{tabular}




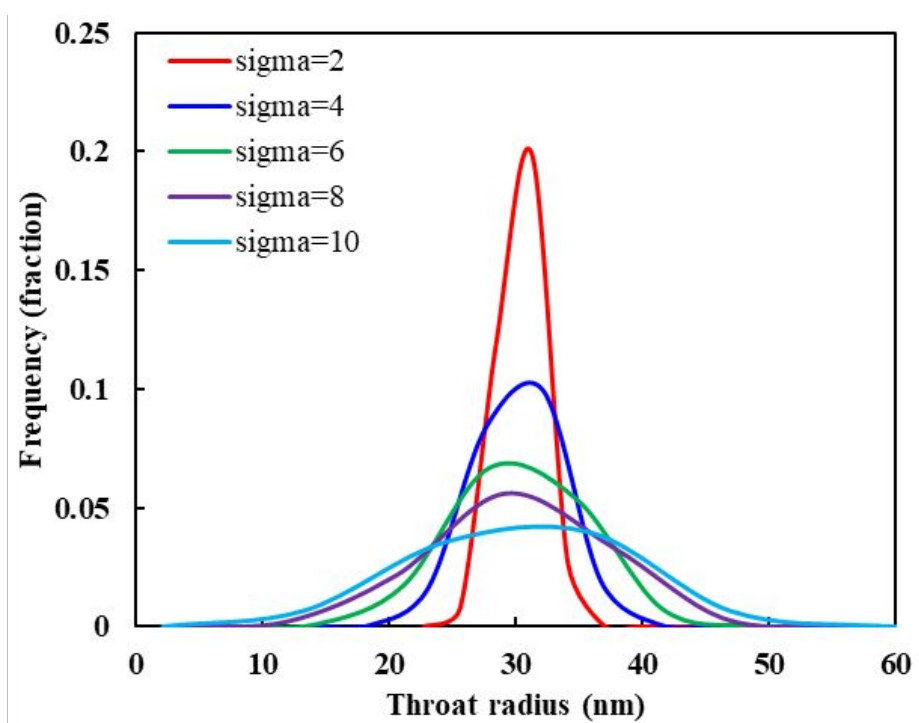

Fig. 4 PSD with various standard deviations at the constant mean pore radius $30 \mathrm{~nm}$

By employing our proposed pore network model, we simulated the steady-state gas flow through the generated networks. The numerical results are shown in Fig. 5 and Fig. 6. As shown in Fig. 5, the critical water saturation decreases with decreasing peak frequency. This is because decreasing peak frequency indicates wider pore size distribution and the proportion of small pores increases which leads to more snap-off pores at the same water saturation. The slippage factor increases as the peak frequency decreases at low water saturation due to the more pronounced gas slippage effect in small pores. However, in contrast, it decreases as the peak frequency decreases because of the predominance of snap off in small pores and a greater proportion of larger pores at high water saturation. The relationship between the intrinsic gas permeability and the water saturation is presented in Fig. 6. The plot clearly shows that the intrinsic permeability decreased as the frequency of the mean pore radius decreased. In addition, the presence of pre-adsorbed water augmented their difference. This is inconsistent with the result from bundle of tube model at dry conditions ${ }^{[52]}$, which concluded that the permeability will increase when the standard deviation increases due to a greater proportion of larger pore. In fact, small throats will control the gas flow rate through nano-porous media to some extent. As shown in Fig. 6b, our result coincides with the result of our previous work ${ }^{[53]}$ at low water saturation. However, at high water saturation they have different trends. This is because at high water saturation snap off 
predominates which leading to a significant decrease in the gas intrinsic permeability and this phenomenon is not captured in the simplified capillary bundle tube model. Therefore, these indicate again that the pore structure characteristics have a significant impact on the gas slippage effect.
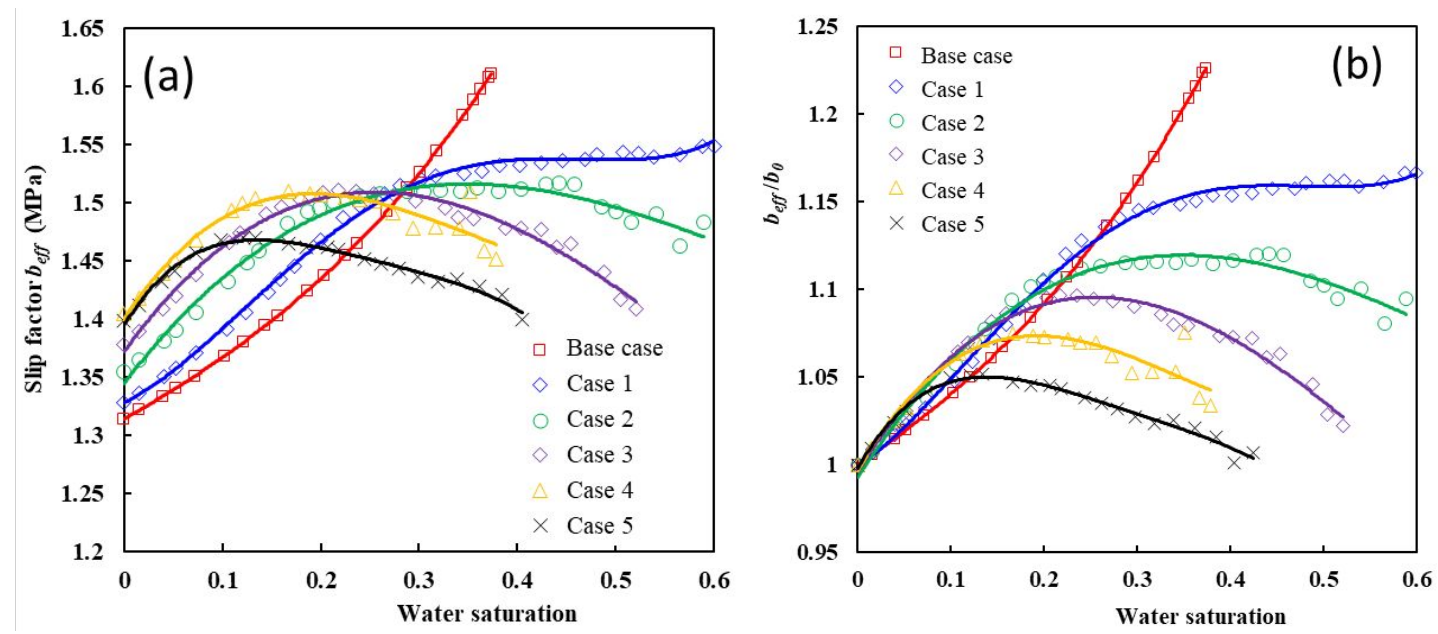

Fig. 5 Two-phase gas slippage characteristic (a) $b_{\text {eff }} \sim S_{w}$ (b) $b_{\text {eff }} / b_{0} \sim S_{w}$
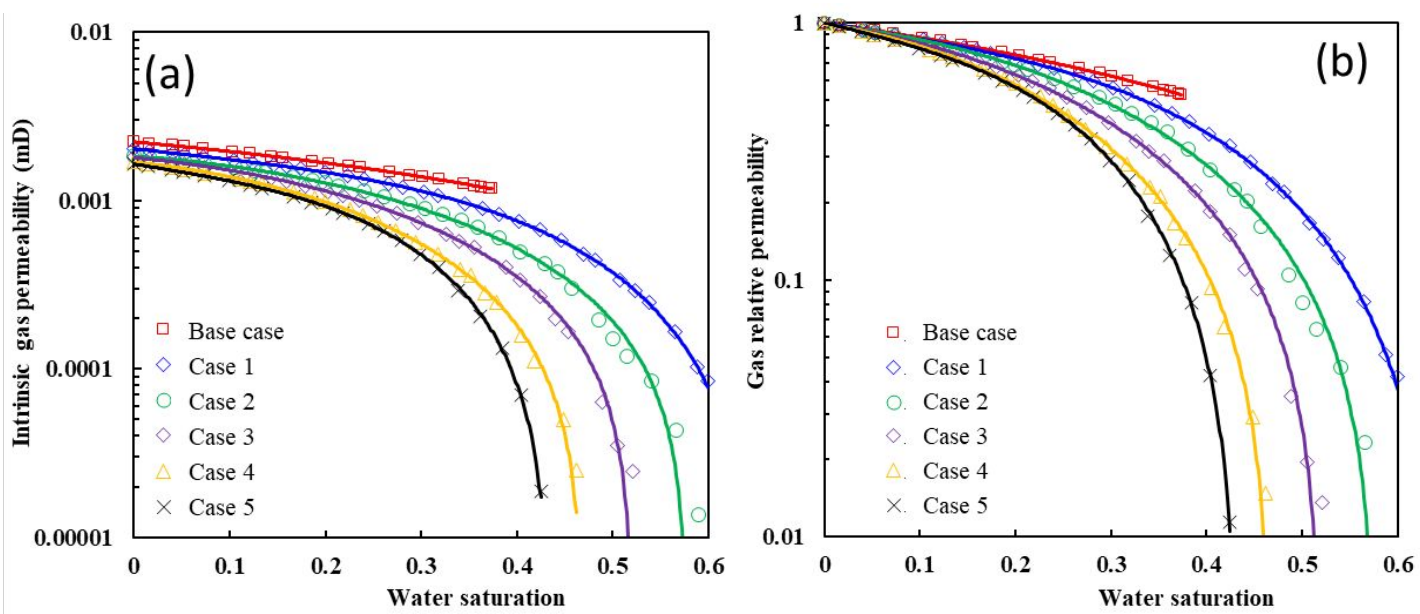

Fig. 6 The relationship between the intrinsic gas permeability and the water saturation

\subsection{Size of mean pore radius}

The mean pore radius is an important parameter to describe the pore size distribution, and it is of great importance on the estimation of the gas-phase permeability of porous medium. Assuming a constant standard deviation of pore size is $10 \mathrm{~nm}$, we generated several networks with different mean pore radius as shown in Table 3 and Fig. 7. 
Table 3 PSD parameters of different mean pore radius size

\begin{tabular}{|c|c|c|c|c|c|}
\hline PSD parameters & $r_{\text {ave }} \mathrm{nm}$ & $\sigma \mathrm{nm}$ & $r_{\min } \mathrm{nm}$ & $r_{\max } \mathrm{nm}$ & $f_{\text {ave }}$ \\
\hline Case 1 & 20 & 10 & 2.03 & 52.06 & 0.039 \\
\hline Case 2 & 30 & 10 & 2.12 & 58.15 & 0.039 \\
\hline Case 3 & 40 & 10 & 3.59 & 72.74 & 0.039 \\
\hline Case 4 & 50 & 10 & 14.32 & 78.37 & 0.039 \\
\hline Case 5 & 60 & 10 & 25 & 96 & 0.039 \\
\hline
\end{tabular}

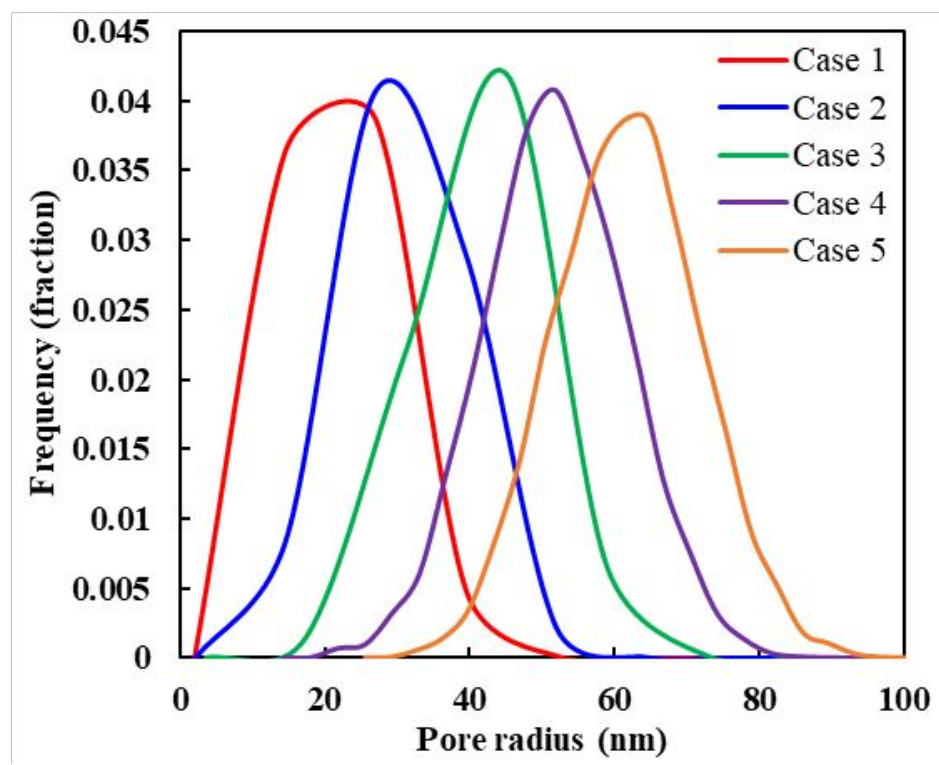

Fig. 7 PSD with various size of mean pore radius at the standard deviation $10 \mathrm{~nm}$

Fig. 8 presents the relationship between the slip factor and the mean pore radius under various water saturations. As expected, Fig. 8a clearly shows that the slip factor increases as a function of the decreasing mean pore radius at dry conditions. Because the interaction between the gas molecules and the wall becomes more significant as the mean pore radius decreases. We also find that the critical water saturation increases firstly, reaches the climax, then decreases with the increase of average pore radius. That's because, at a certain water saturation, free gas saturation increases first and then decreases as the mean pore radius increased (as shown in Fig. 9). The free gas saturation is dependent on water saturation and trapped gas saturation formed by water condensation and blocking. As shown in Fig. 10a, the water saturation decreases with an increase in the pore radius at the same humidity and the rate slows down. The critical 
water saturation for a single pore at which water condensation occurs decreases as the radius rises (Fig. 10b). Similarly, Liu et al. ${ }^{[19]}$ found, there's an inflection point that the critical water saturation changes with the core coefficient which is defined as the ratio of absolute permeability and porosity.
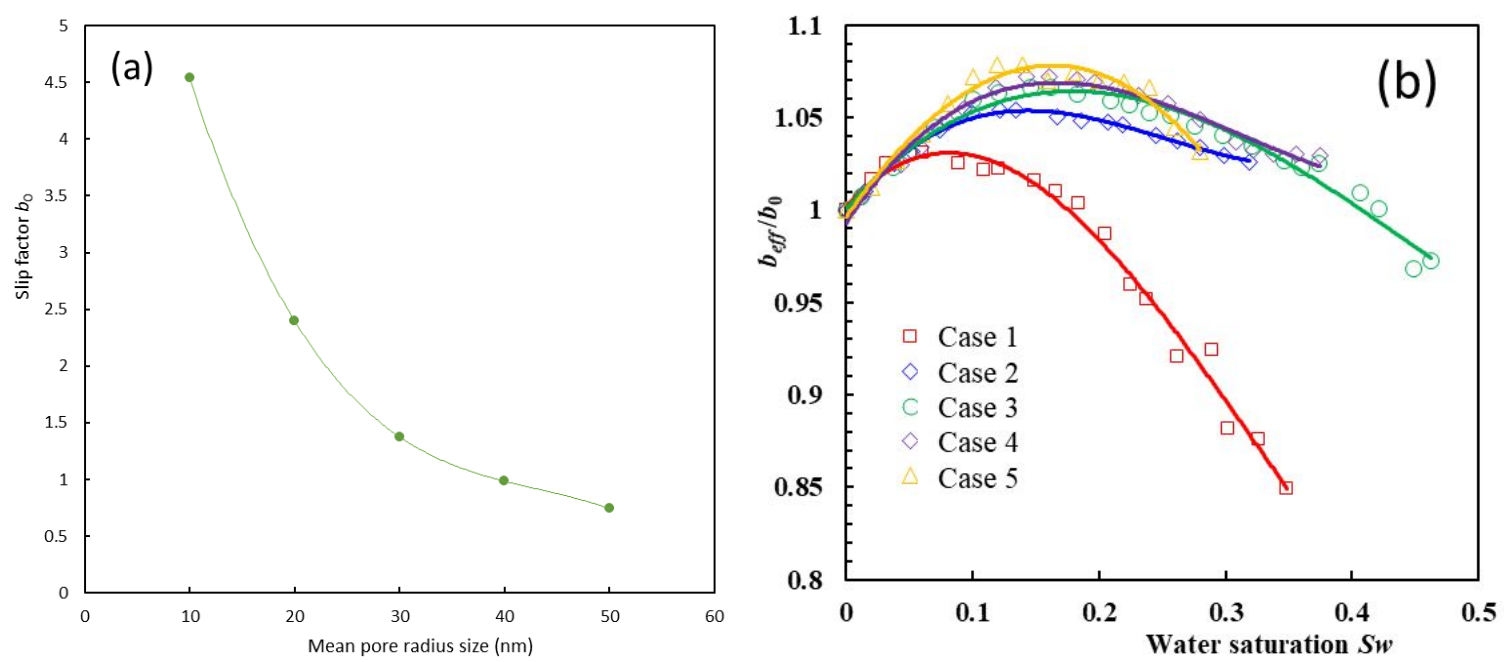

Fig. 8 Two-phase gas slippage characteristic (a) $b_{\text {eff }} \sim S_{w}$ (b) $b_{\text {eff }} / b_{0} \sim S_{w}$

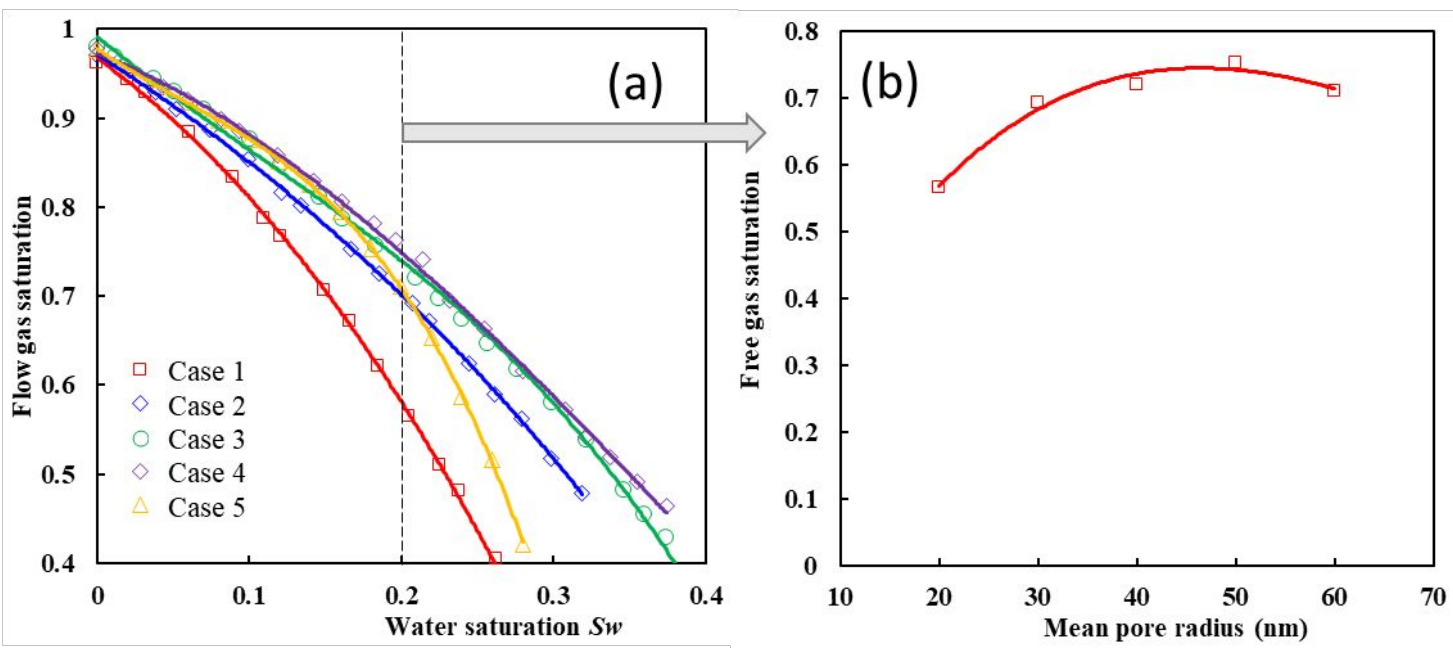

Fig. 9 Dependance of free gas saturation on (a) water saturation (b) mean pore radius when $S_{w}$

$$
=0.20
$$



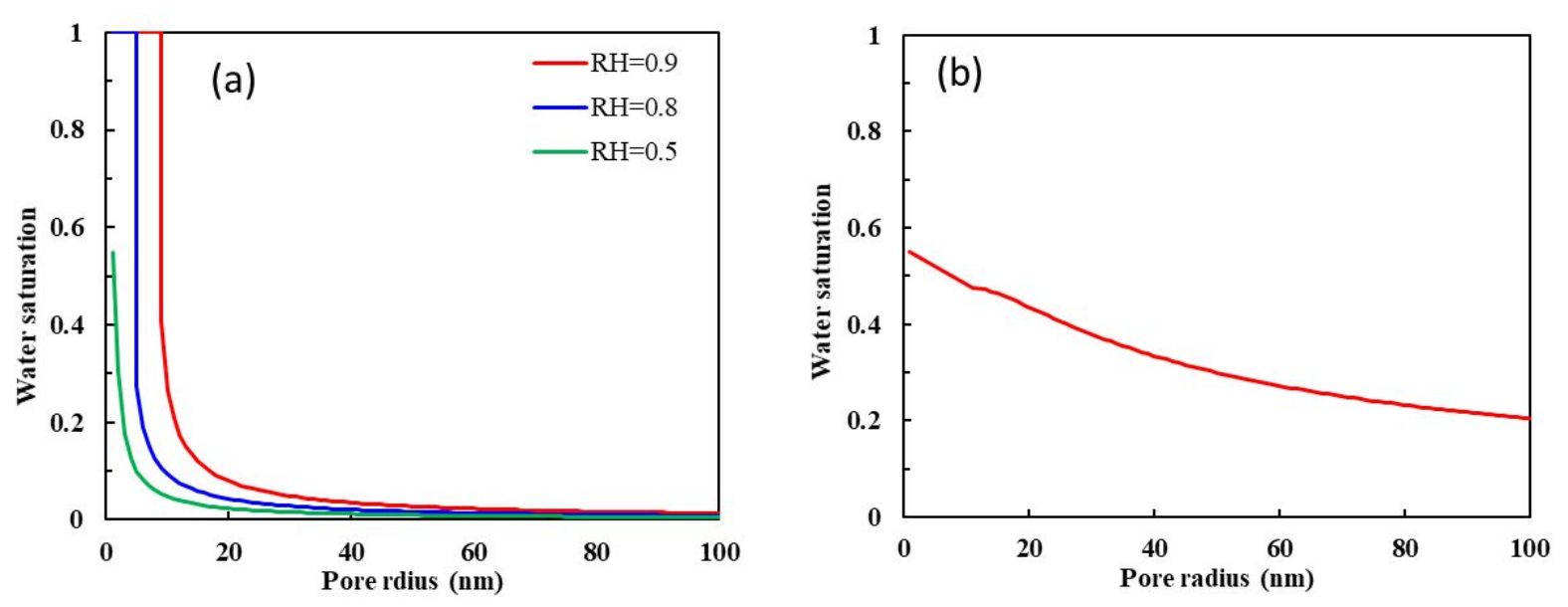

Fig. 10 The relationship between water saturation and pore radius for single pore (a) with various humidity (b) with critical humidity

\subsection{Aspect ratio}

In this section, the effect of the aspect ratio on the slippage characteristics is studied by changing the throat size distribution functions while pore size distribution is assumed to be constant. The pore throat size distributions are shown in Table 4 and Fig. 11.

The relationship between the gas slip factor and water saturation is shown in Fig. 12. As illustrated in Fig. 12a, the slippage factor rises with an increase in the aspect ratio at dry conditions due to decreasing throat radii. In addition, Fig. $12 b$ indicates the decreasing critical water saturation with the increasing aspect ratio. This is because water condensation is more likely to occur in small throats. As water condensation becomes predominant, the slippage factor tends to decrease due to the increasing equivalent radius which results from the removal of small pores and throats.

Table 4 PSD parameters of different mean throat radius size

\begin{tabular}{|c|c|c|c|c|c|}
\hline PSD parameters & $\begin{array}{c}\text { Aspect } \\
\text { ratio }\end{array}$ & $\sigma \mathrm{nm}$ & $r_{\text {min }} \mathrm{nm}$ & $r_{\text {max }} \mathrm{nm}$ & $f_{\text {ave }}$ \\
\hline Case 1 & 1.5 & 20 & 12.84 & 28.80 & 0.18 \\
\hline Case 2 & 2.0 & 15 & 7.08 & 22.49 & 0.18 \\
\hline Case 3 & 3.0 & 10 & 2.12 & 17.80 & 0.18 \\
\hline
\end{tabular}




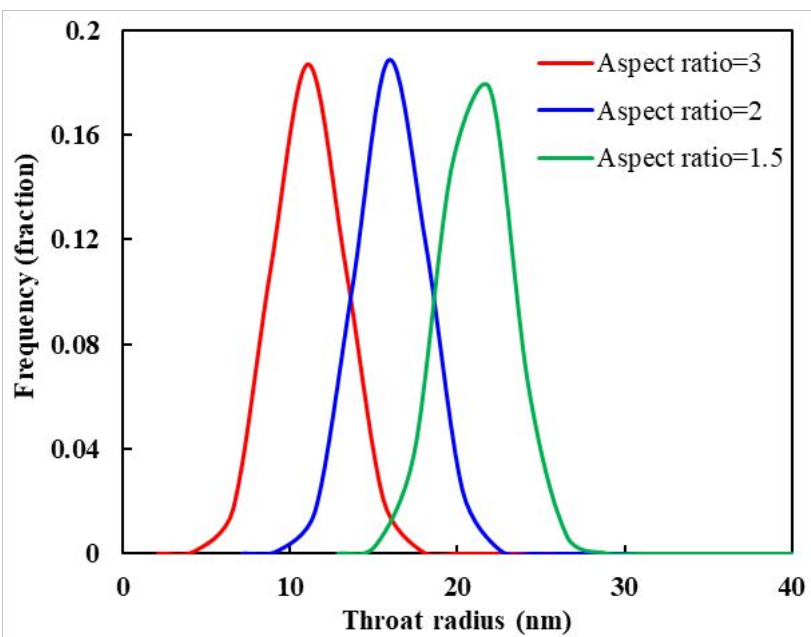

Fig. 11 Throat size distribution with various aspect ratio at same pore size distribution
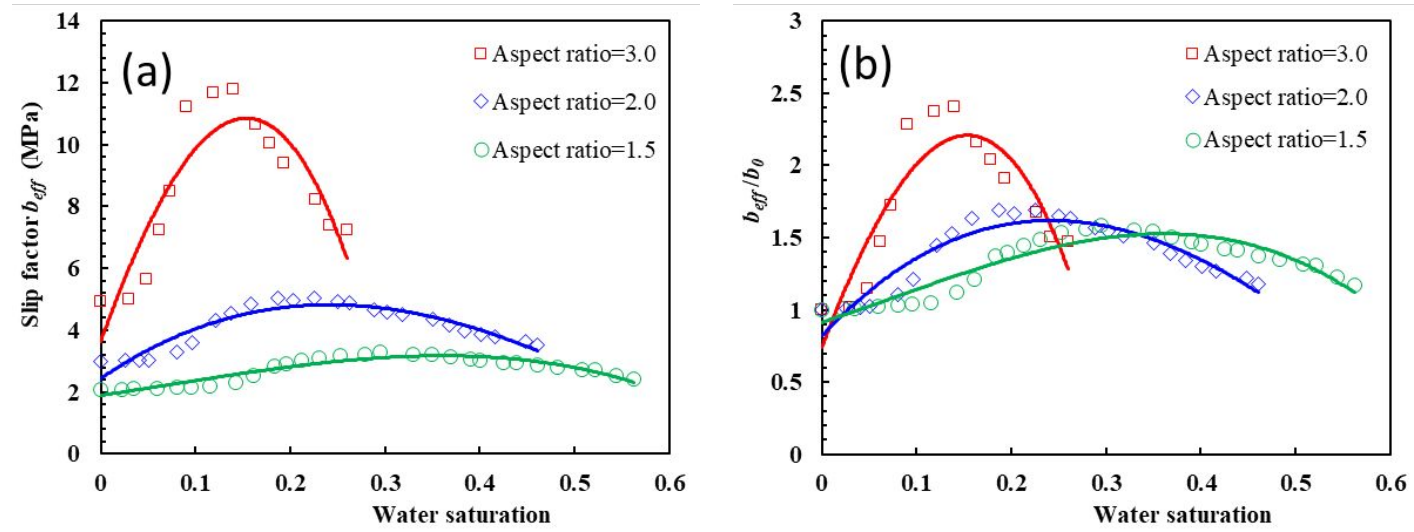

Fig. 12 Two-phase gas slippage characteristic with different aspect ratio (a) $b_{\text {eff }} \sim S_{w}$ (b) $b_{\text {eff }} /$

$$
b_{0} \sim S_{w}
$$

\subsection{Coordination number}

Coordination number is an important parameter that characterizes the topology and connectivity of porous media ${ }^{[54]}$. Previous studies revealed that real rock samples have a broad distribution of coordinate numbers ${ }^{[55,56]}$. As in Zhang et al.'s work ${ }^{[29]}$, we choose normal probability distribution to generate coordination numbers for each pores. The mean coordination number is applied to describe the connectivity of porous media in our study. As shown in Fig. 9, we generate three stochastic networks with various mean coordination numbers and investigate its effect on slippage characteristics.

The results are shown in Fig. 14 and Fig. 15. The gas slippage factor decreases with the mean coordination number, while the intrinsic permeability increases as the coordination number increases at dry conditions (see Fig. 14a and Fig. 15a). This is due 
to better connectivity when the mean coordination number increased, and results in increased gas flow ${ }^{[57]}$. Fig. $14 \mathrm{~b}$ indicates that the critical water saturation increases with an increase of the mean coordination number due to that the trapped gas becomes less favorable in a well-connected pore space ${ }^{[58]}$.

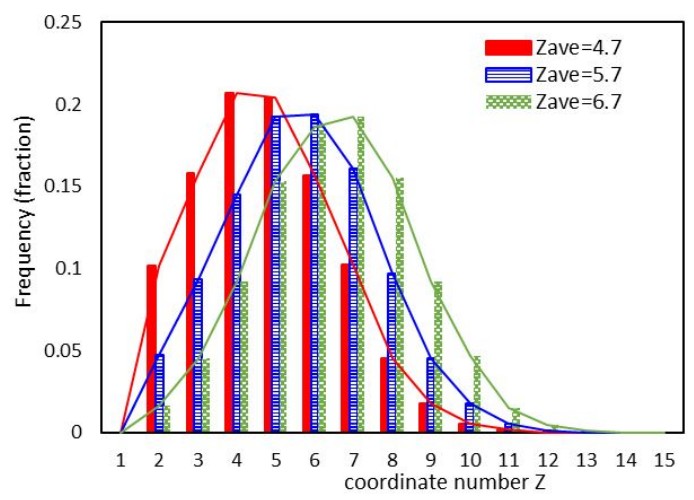

Fig. 13 Distribution of the coordinate number
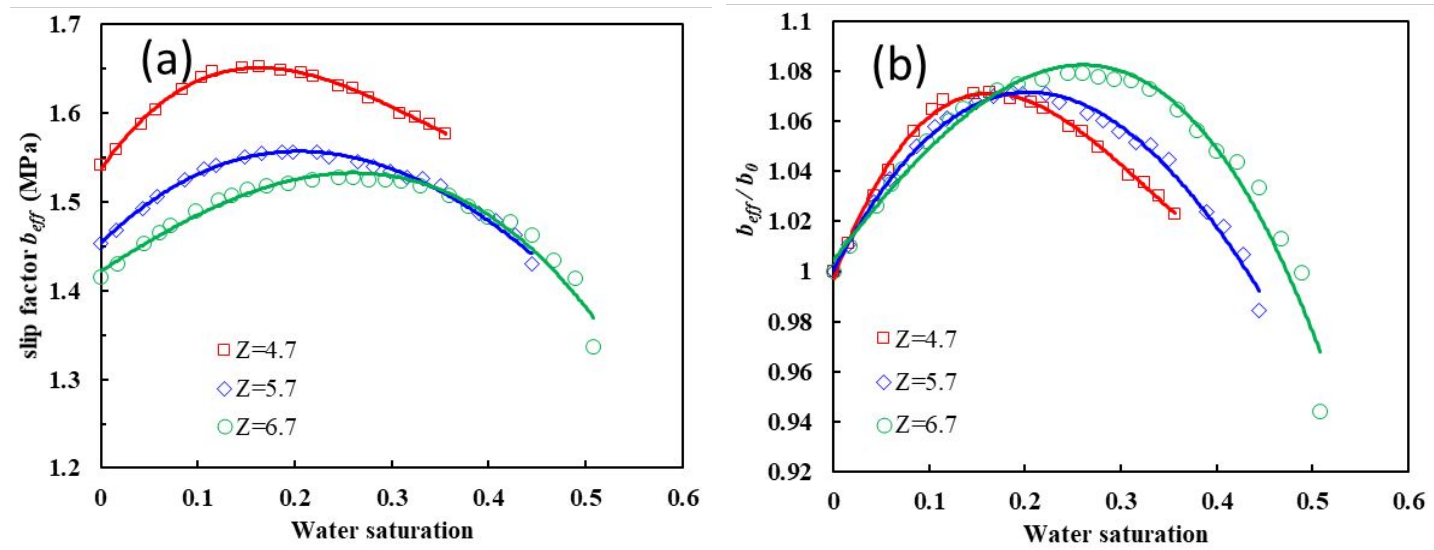

Fig. 14 Two-phase gas slippage characteristic (a) $b_{\text {eff }} \sim S_{w}$ (b) $b_{\text {eff }} / b_{0} \sim S_{w}$
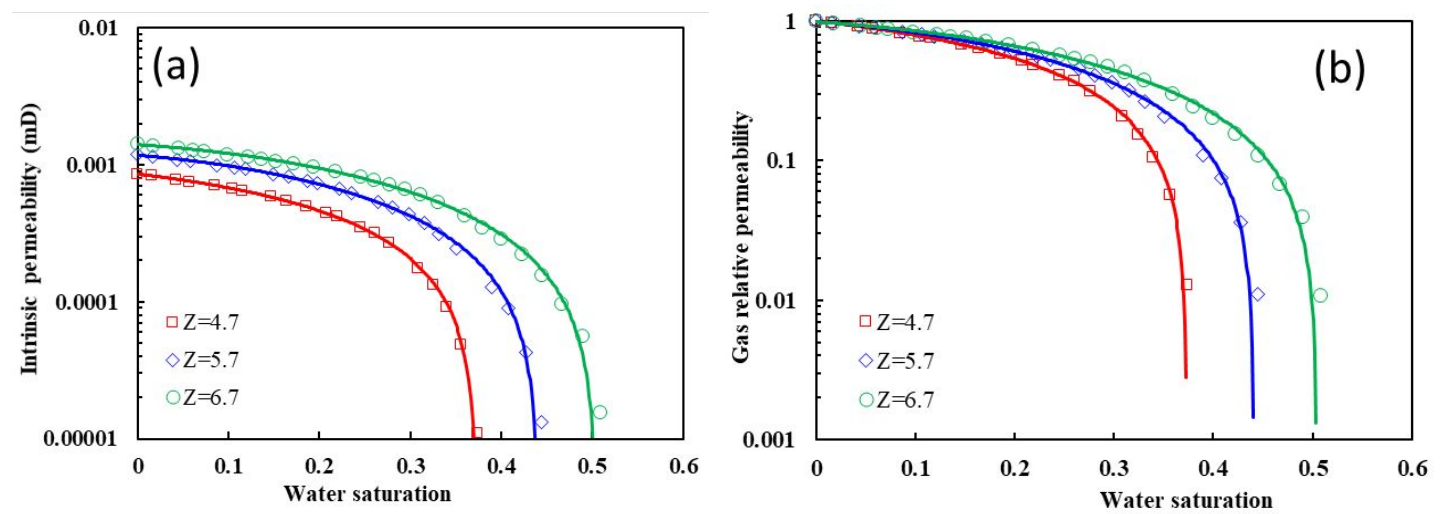

Fig. 15 The relationship between the intrinsic gas relative permeability and the water saturation 


\subsection{Limitation}

To our knowledge, this is the very first work on the two-phase gas slippage effect in nano-porous media using pore network model. The classic Klinkenberg slip theory is adopted to calculate the intrinsic permeability and the slippage factor. In recent years, the classical Klinkenberg's theory was modified for ultra-low-permeability porous media applications to improve the predictability of Klinkenberg slip theory ${ }^{[5-7]}$. Their research showed that the gas slippage factor is not constant. It could be included in our future study.

The present model is based on the assumption that the pores and throats are hydrophilic and circular, while the gas-water two-phase flow behavior in organic pores will be different and more mechanisms such as gas adsorption/desorption, surface diffusion are needed to be incorporated in the methodology [43, 59], which could be investigated by extending the proposed pore network model. Other properties of solid surfaces also have a great influence on the fluid distribution and multiphase flow behavior ${ }^{[60,61]}$. Li et al. ${ }^{[43]}$ found that the property of solid surface affects the stability and thickness of water film. Huang et al. ${ }^{[62]}$ found that slip lengths on different surfaces are found to be a function of the static contact angle. The effect of these factors needs to be investigated further.

On the other hand, the shapes of pores and throats are various and it's a rather ideal assumption. The shape of pores is a key parameter that influences the transportation of single-phase or multiphase flow ${ }^{[50,63,64]}$. Li et al. ${ }^{[21]}$ found that for circular pores the effective radius decreases continuously with an increase in water saturation which leads to a rising slippage factor. And for angular pores, the cross-section shape changes due to the existence of corner water and the slippage factor could decrease as the water saturation increases. However, the results are concluded using the capillary bundle model and need to be verified in the complex porous media. In our future study, we will take this important factor into consideration.

\section{CONCLUSIONS}

A static pore network model, considering dynamics of water distribution, real gas 
effect and gas transport mechanisms, is proposed to investigate the influence of pore structure on slippage effect in unsaturated tight formation. The model has been validated and proved its capability to capture the effect of water on gas transport behavior in the nano-porous media. The results indicate that:

- There is a critical water saturation that separates the uptrend and downtrend of the gas slippage factor due to an increase in water saturation. This critical water saturation is dependent on the pore structure characteristics and connectivity of the porous media.

- The critical water saturation increases with the increasing frequency of mean pore radius and decreasing aspect ratio due to weaker heterogeneity. Furthermore, it increases as the coordination number increases due to better connectivity.

- The relationship between critical water saturation and mean pore radius is nonmonotonic. It increases firstly, reaches the climax, then decreases with the increase of average pore radius.

\section{Corresponding Author}

*E-mail: yingfang.zhou@abdn.ac.uk tobiascheuing@163.com

\section{Notes}

The authors declare no competing financial interest.

\section{ACKNOWLEDGMENTS}

We acknowledge the Beijing Natural Science Foundation of China (No. 2204093), Science Foundation of China University of Petroleum, Beijing (No.2462018YJRC033) and financial support from China Scholarship Council ((No. 201906440134).

\section{REFERENCES}

1. Klinkenberg, L.J., The Permeability Of Porous Media To Liquids And Gases, in Drilling and Production Practice. 1941, American Petroleum Institute: New York, New York. p. 14. 
2. Heid, J.G., et al., Study of the Permeability of Rocks to Homogeneous Fluids, in Drilling and Production Practice. 1950, American Petroleum Institute: New York, New York. p. 17.

3. Jones, F.O. and W.W. Owens, A Laboratory Study of Low-Permeability Gas Sands. Journal of Petroleum Technology, 1980. 32(09): p. 1631-1640.

4. Sampath, K. and C.W. Keighin, Factors Affecting Gas Slippage in Tight Sandstones of Cretaceous Age in the Uinta Basin. Journal of Petroleum Technology, 1982. 34(11): p. 2715-2720.

5. Fathi, E., A. Tinni, and I.Y. Akkutlu, Correction to Klinkenberg slip theory for gas flow in nano-capillaries. International Journal of Coal Geology, 2012. 103: p. 51-59.

6. Ashrafi Moghadam, A. and R. Chalaturnyk, Expansion of the Klinkenberg's slippage equation to low permeability porous media. International Journal of Coal Geology, 2014. 123: p. 2-9.

7. Sabet, S., et al., An extended Kozeny-Carman-Klinkenberg model for gas permeability in micro/nano-porous media. Physics of Fluids, 2019. 31(11): p. 112001.

8. Zhu, W.C., et al., Analysis of coupled gas flow and deformation process with desorption and Klinkenberg effects in coal seams. International Journal of Rock Mechanics and Mining Sciences, 2007. 44(7): p. 971-980.

9. Wang, G., et al., Improved apparent permeability models of gas flow in coal with Klinkenberg effect. Fuel, 2014. 128: p. 53-61.

10. Firouzi, M., et al., Klinkenberg effect on predicting and measuring helium permeability in gas shales. International Journal of Coal Geology, 2014. 123: p. $62-68$.

11. Bennion, D.B. and F.B. Thomas, Formation Damage Issues Impacting the Productivity of Low Permeability, Low Initial Water Saturation Gas Producing Formations. Journal of Energy Resources Technology, 2005. 127(3): p. 240247.

12. Yu, J., et al., A review on water in low rank coals: The existence, interaction with 
coal structure and effects on coal utilization. Fuel Processing Technology, 2013. 106: p. 9-20.

13. Rushing, J.A., K.E. Newsham, and K.C. Van Fraassen, Measurement of the TwoPhase Gas Slippage Phenomenon and Its Effect on Gas Relative Permeability in Tight Gas Sands, in SPE Annual Technical Conference and Exhibition. 2003, Society of Petroleum Engineers: Denver, Colorado. p. 9.

14. Estes, R.K. and P.F. Fulton, Gas Slippage and Permeability Measurements. Journal of Petroleum Technology, 1956. 8(10): p. 69-73.

15. Li, J., et al., Effect of water saturation on gas slippage in tight rocks. Fuel, 2018. 225: p. 519-532.

16. Yuan, X., et al., Spontaneous imbibition in coal: Experimental and model analysis. Journal of Natural Gas Science and Engineering, 2019. 67: p. 108-121.

17. Li, K. and R.N. Horne, Experimental Study of Gas Slippage in Two-Phase Flow. SPE Reservoir Evaluation \& Engineering, 2004. 7(06): p. 409-415.

18. Wu, Q., et al., Optic Imaging of Two-Phase-Flow Behavior in 1D Nanoscale Channels. SPE Journal, 2014. 19(05): p. 793-802.

19. Liu, X., J. Yan, and Y. Liu, Gas Slippage Effect in Low Permeability Water-bearing Gas Reservoirs, in SPE Reservoir Characterisation and Simulation Conference and Exhibition. 2011, Society of Petroleum Engineers: Abu Dhabi, UAE. p. 9.

20. Shi, J., et al., Gas permeability model considering rock deformation and slippage in low permeability water-bearing gas reservoirs. Journal of Petroleum Science and Engineering, 2014. 120: p. 61-72.

21. Li, J., et al., Effect of water saturation on gas slippage in circular and angular pores. AIChE Journal, 2018. 64(9): p. 3529-3541.

22. Sun, Z., et al., Gas Flow Behavior through Inorganic Nanopores in Shale Considering Confinement Effect and Moisture Content. Industrial \& Engineering Chemistry Research, 2018. 57(9): p. 3430-3440.

23. Yu, L. and N.C. Wardlaw, Mechanisms of nonwetting phase trapping during imbibition at slow rates. Journal of Colloid and Interface Science, 1986. 109(2): p. $473-486$. 
24. Tanino, Y. and M.J. Blunt, Capillary trapping in sandstones and carbonates: Dependence on pore structure. Water Resources Research, 2012. 48.

25. FATT, I., The network model of porous media. I. capillary pressure characteristics. Petrol. Trans. AIME, 1956. 207: p. 144-159.

26. Fatt, I., The network model of porous media. 2. Dynamic properties of a single size tube network. Transactions of the American institute of mining and metallurgical engineers, 1956. 207(7): p. 160-163.

27. Fatt, I., The network model of porous media. 3. Dynamic properties of networks with tube radius distribution. Transactions of the American institute of mining and metallurgical engineers, 1956. 207(7): p. 164-181.

28. Song, W., et al., Dynamic pore network modelling of real gas transport in shale nanopore structure. Journal of Petroleum Science and Engineering, 2020. 184.

29. Zhang, P., et al., Micro/Nano-pore Network Analysis of Gas Flow in Shale Matrix. Scientific Reports, 2015. 5(1): p. 13501.

30. Mehmani, A., M. Prodanović, and F. Javadpour, Multiscale, Multiphysics Network Modeling of Shale Matrix Gas Flows. Transport in Porous Media, 2013. 99(2): p. 377-390.

31. Silin, D. and T. Patzek, Pore space morphology analysis using maximal inscribed spheres. Physica A: Statistical Mechanics and its Applications, 2006. 371(2): p. 336-360.

32. Dong, H. and M.J. Blunt, Pore-network extraction from micro-computerizedtomography images. Physical Review E, 2009. 80(3): p. 036307.

33. Roslin, A., et al., 3D pore system reconstruction using nano-scale $2 D$ SEM images and pore size distribution analysis for intermediate rank coal matrix. Fuel, 2020. 275: p. 117934.

34. Lindquist, W.B., et al., Medial axis analysis of void structure in three-dimensional tomographic images of porous media. Journal of Geophysical Research: Solid Earth, 1996. 101(B4): p. 8297-8310.

35. ØRen, P.-E. and S. Bakke, Process Based Reconstruction of Sandstones and Prediction of Transport Properties. Transport in Porous Media, 2002. 46(2): p. 
311-343.

36. de Chalendar, J.A., C. Garing, and S.M. Benson, Pore-scale modelling of Ostwald ripening. Journal of Fluid Mechanics, 2018. 835: p. 363-392.

37. Idowu, N.A. and M.J. Blunt, Pore-scale modelling of rate effects in waterflooding. Transport in porous media, 2010. 83(1): p. 151-169.

38. Raoof, A. and S.M. Hassanizadeh, A new method for generating pore-network models of porous media. Transport in porous media, 2010. 81(3): p. 391-407.

39. Valvatne, P.H., Predictive pore-scale modelling of multiphase flow. 2004, Department of Earth Science and Engineering, Imperial College London.

40. Zhang, T., et al., A discrete model for apparent gas permeability in nanoporous shale coupling initial water distribution. Journal of Natural Gas Science and Engineering, 2018. 59: p. 80-96.

41. Zhang, Y., et al., New theoretical model to calculate the apparent permeability of shale gas in the real state. Journal of Natural Gas Science and Engineering, 2019. 72: p. 103012.

42. Li, J., et al., Thickness and stability of water film confined inside nanoslits and nanocapillaries of shale and clay. International Journal of Coal Geology, 2017. 179: p. 253-268.

43. Li, J., et al., Water distribution characteristic and effect on methane adsorption capacity in shale clay. International Journal of Coal Geology, 2016. 159: p. 135154.

44. Feng, D., et al., Nanoconfinement Effect on Surface Tension: Perspectives from Molecular Potential Theory. Langmuir, 2020.

45. Feng, D., et al., Wettability effects on phase behavior and interfacial tension in shale nanopores. Fuel, 2021. 290: p. 119983.

46. Zarragoicoechea, G.J. and V.A. Kuz, van der Waals equation of state for a fluid in a nanopore. Physical Review E, 2002. 65(2): p. 021110.

47. Wu, K., et al., Methane storage in nanoporous material at supercritical temperature over a wide range of pressures. Scientific Reports, 2016. 6(1): p. 33461.

48. Zéberg-Mikkelsen, C.K., S.E. Quiñones-Cisneros, and E.H. Stenby, Viscosity 
Modeling of Light Gases at Supercritical Conditions Using the Friction Theory. Industrial \& Engineering Chemistry Research, 2001. 40(17): p. 3848-3854.

49. Wu, K., Z. Chen, and X. Li, Real gas transport through nanopores of varying crosssection type and shape in shale gas reservoirs. Chemical Engineering Journal, 2015. 281: p. 813-825.

50. Ali Beskok, G.E.K., REPORT: A MODEL FOR FLOWS IN CHANNELS, PIPES, AND DUCTS AT MICRO AND NANO SCALES. Microscale Thermophysical Engineering, 1999. 3(1): p. 43-77.

51. Sinha, S., et al., Steady-State Permeability Measurements on Intact Shale Samples at Reservoir Conditions - Effect of Stress, Temperature, Pressure, and Type of Gas, in SPE Middle East Oil and Gas Show and Conference. 2013, Society of Petroleum Engineers: Manama, Bahrain. p. 15.

52. Cao, R.Y., et al., A New Model for Determining the Effective Permeability of Tight Formation. Transport in Porous Media, 2016. 112(1): p. 21-37.

53. Zhang, T., et al., An analytical model for relative permeability in water-wet nanoporous media. Chemical Engineering Science, 2017. 174(Supplement C): p. 1-12.

54. Vasilyev, L., A. Raoof, and J.M. Nordbotten, Effect of Mean Network Coordination Number on Dispersivity Characteristics. Transport in Porous Media, 2012. 95(2): p. 447-463.

55. Ioannidis, M.A., et al., Comprehensive Pore Structure Characterization Using 3D Computer Reconstruction and Stochastic Modeling, in SPE Annual Technical Conference and Exhibition. 1997, Society of Petroleum Engineers: San Antonio, Texas. p. 9.

56. Øren, P.-E. and S. Bakke, Reconstruction of Berea sandstone and pore-scale modelling of wettability effects. Journal of Petroleum Science and Engineering, 2003. 39(3): p. 177-199.

57. Chen, M., et al., Pore network modelling of fluid flow in tight formations considering boundary layer effect and media deformation. Journal of Petroleum Science and Engineering, 2019. 180: p. 643-659. 
58. Singh, K., et al., Imbibition in porous media: correlations of displacement events with pore-throat geometry and the identification of a new type of pore snap-off. 2019.

59. Sun, Z., et al., Molecular Dynamics of Methane Flow Behavior through Realistic Organic Nanopores under Geologic Shale Condition: Pore size and Kerogen Types. Chemical Engineering Journal, 2020: p. 124341.

60. Zhang, T., et al., Mesoscopic method to study water flow in nanochannels with different wettability. Physical Review E, 2020. 102(1): p. 013306.

61. Zhang, T., et al., Upscaling Water Flow in Composite Nanoporous Shale Matrix Using Lattice Boltzmann Method. Water Resources Research, 2020. 56(4): p. e2019WR026007.

62. Huang, D.M., et al., Water Slippage versus Contact Angle: A Quasiuniversal Relationship. Physical Review Letters, 2008. 101(22): p. 226101.

63. Duan, Z. and Y.S. Muzychka, Slip flow in elliptic microchannels. International Journal of Thermal Sciences, 2007. 46(11): p. 1104-1111.

64. Shi, J., et al., Effect of Pore Shape on Nanoconfined Gas Flow Behavior: Implication for Characterizing Permeability of Realistic Shale Matrix. Industrial \& Engineering Chemistry Research, 2019. 58(20): p. 8835-8846. 
TABLE OF CONTENTS GRAPHIC

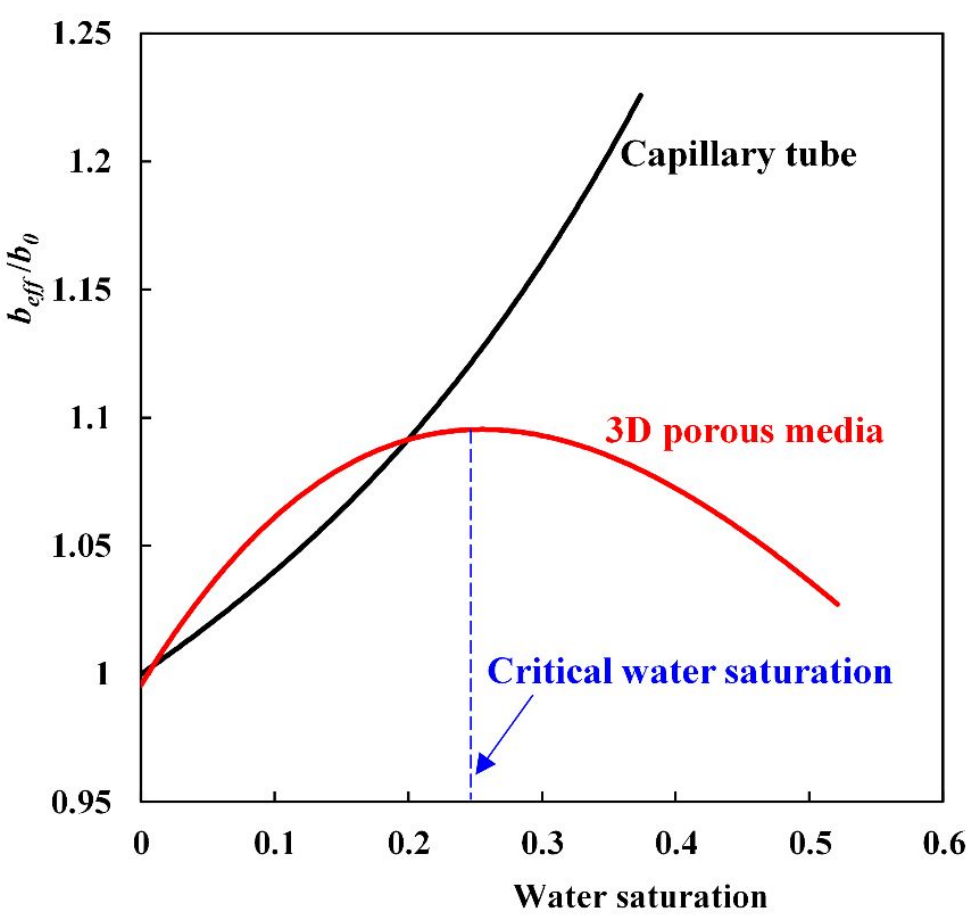




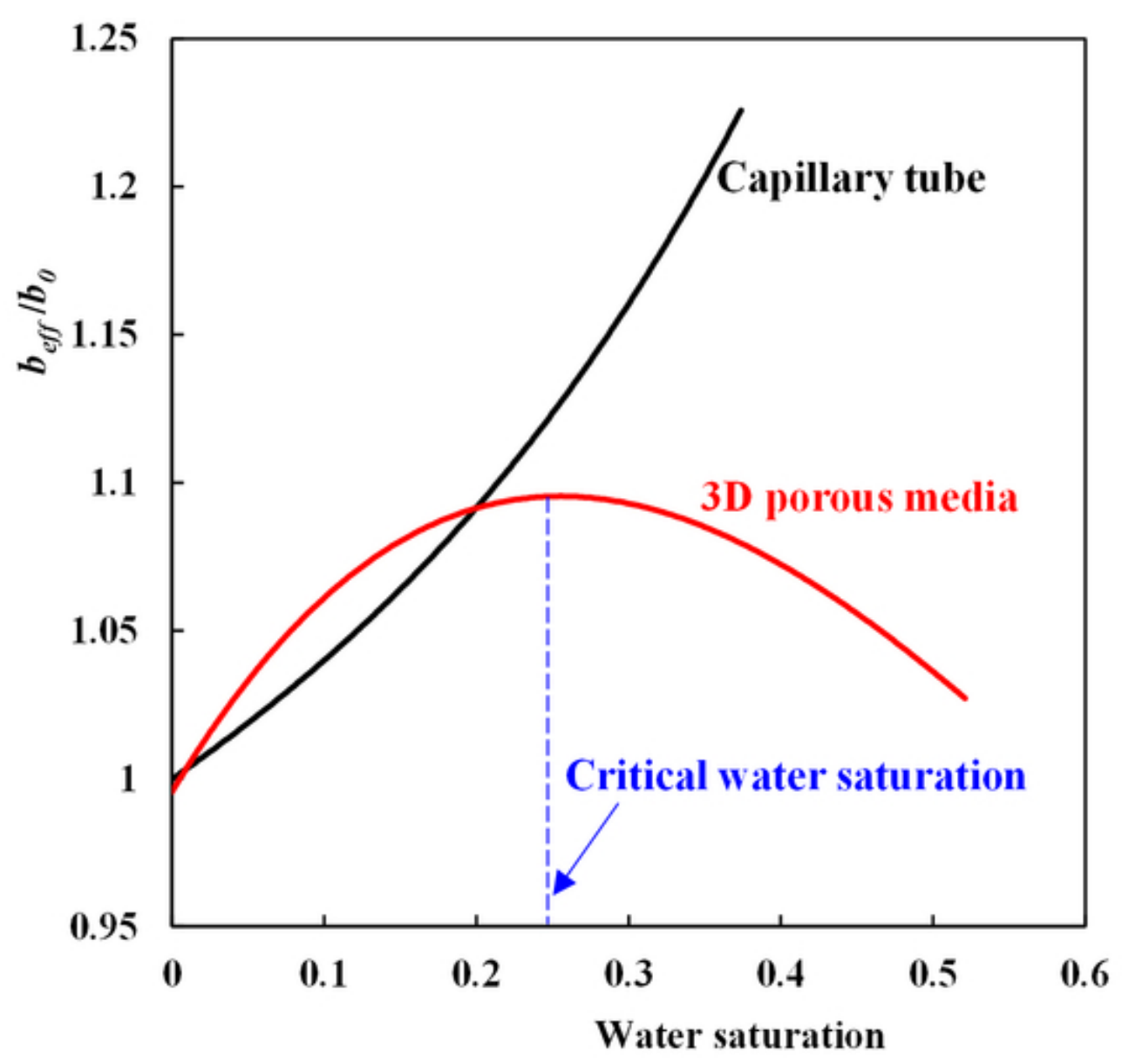

$45 \times 43 \mathrm{~mm}(300 \times 300$ DPI $)$ 